\author{
William A. Corsaro \\ Indiana University, Bloomington Indiana \\ USA
}

\title{
PEER CULTURE AND ADULT-CHILD RELATIONS ${ }^{1}$
}

\begin{abstract}
The article at hand addresses adult-child relations, comparing them in two settings - Italy and the United States. More specifically, I will be investigating family and community relations with the children and school institutions. A longitudinal ethnography in Italy, conducted with a colleague, permitted us to focus on the children's transitions from preschool to elementary school and even into middle school. When comparing the Italian outcomes (where children normally stay in the same group with the same teacher) with my earlier work in American preschools (where children normally change groups and teachers), I became more aware of the vital role which teachers, parents, community leaders, and volunteers play in supporting the peer cultures of young children. Therefore, this article will share insights gathered by comparing my observations and experiences in Italy and the USA, looking first at teachers, then considering family members, and ultimately the general community. Among other things, special notice will be taken of time schedules, emotions and bonding, free play, field trips, civic engagement, etc. This discussion will close with some reflections on my own relationship with the children and my own contributions to their peer cultures in my role as a researcher, as an adult, and as a friend in their lives.
\end{abstract}

Key words: adult-child relations, peer culture, transitions, preschool, elementary school, community, participatory action research

\section{Introduction}

Although peer culture and adult-child relations is a topic I have much experience with because my research has primarily focused on children's peer relations and cultures, I have less often addressed adult-child relations. When I have discussed adults in my research, it is usually teachers and how they influence peer culture or, more recently, how they prepare children for the transition from preschool to elementary school. However, my recent research in Modena, Italy has made me more aware of the importance of how children's peer cultures are affected by the relationship of the family and community with children and preschool and elementary school institutions. In this study my Italian

1 This is a revised version of a paper first published in Corsaro W. (2004). Peer culture and adultchild relations. "Stockholm Lectures in Educology", 3. Stockholm University, Department of Education. 
colleague, Luisa Molinari, and I conducted a longitudinal ethnography of a group of children's transition from preschool to elementary school. We then continued to observe and follow the children throughout elementary school and on to middle school. In the doing so, we not only experienced the process of transition with the children, but we also interviewed teachers and parents. We also participated in field trips, parties and activities in the schools involving parents and grandparents, and attended larger community events for children over a seven year period.

This research when compared with my earlier work in preschools in the United States made me more aware of the vital role adults (teachers, parents, and community leaders and volunteers) can play in supporting and enriching young children's peer cultures. In this article I share some of these insights by comparing my experiences in Italy and the United States looking first at teachers and then going on to consider family members and the community more generally. I end the discussion with some reflection on my own relationship with children and my contributions to their peer cultures in my role as an adult researcher.

\section{Teachers and peer culture}

A major factor affecting teacher-child relations in early education settings is the structure and organization of classes. Most preschools and all elementary schools structure children into age groups. However, a big difference between Italy and the United States is that in Italy children normally stay in the same group with the same teachers throughout their time in these educational institutions (for three years in preschool and five years in elementary school), while in the United States children normally change teachers and often group composition changes as children move from one group or class to another. In Italy we found that keeping teachers and children together in this way resulted in strong communal bonds between teachers and students, close relationships between teachers and parents, and a highly integrated peer cultures. Teachers, parents and children get to know each other well both at the individual and group level.

\section{Individual teacher-child relations}

At the individual level in Italy teachers identify the strengths and needs of particular children, and have ample time to address them both in individual interactions and group projects. Thus, the diagnosis of a child's particular needs and strengths and plans of action in the activities of the group, individually with the child, and communications with parents takes place over a longer period of evaluation and practice. In the United States, in contrast, the identification of particular student's strengths and especially needs must take place quickly and often without sufficient observation before moving to plans of action. Further, children with special needs are often labeled as having particular 
problems when they move into different classes with new teachers and peers. In many cases, the particular problem can be exaggerated and the child can have problems adjusting to the new group. These discontinuities in early educational transitions can have long term negative effects on the child's educational career.

In our interviews with teachers in Modena we were struck by their insights in their evaluation of the children over time. How some children started out with strong academic or social skills which the teachers built on and nourished, while other children needed special attention or help early on, but made excellent progress both academically and socially. Also the teachers were aware of any personal family problems or disruptions that could affect individual children's behavior or progress in the school due to frequent family meetings and excellent rapport with parents.

On the other hand, even the best teachers in my work in the United States felt some children had not made the progress they would have liked during the one school year they had with the children. They wished they had more time to work with such children and bemoaned the fact that there was relatively little interaction with parents.

\section{Teacher-children interaction in group activities}

At the group level keeping teachers and children together over multiple years has important positive effects on teacher-children relationship in a number of ways. In most preschools the curriculum is composed of meeting times for planning and discussion, teacher directed short and long term projects, and free play in various areas of the classrooms and outside areas which are conducive to a variety of types of play.

Meeting times in Italian and American preschools I have studied differed significantly in terms of the way the teachers and children interacted with each other. In a private American preschool for four and five year olds I studied recently in Bloomington, Indiana meeting time usually began with routines in which individual children had the opportunity to perform certain task related to their developing literacy. For example, the teachers choose a child to print the numerical date on a calendar, select a picture which corresponded to the day's weather, and then finish by printing her or his name on a small blackboard. The kids relished their opportunity to participate in these activities, especially the printing of their names which all of them could do without help.

After a short good morning greeting and sometimes a song, each child took a turn offering something to the group in a show and tell format. Usually children selected books to talk about during their turns. However, children could also display and talk about a picture, present a narrative about something that happened to them, or display and talk about their journals. The talk about journals was infrequent, but much encouraged by the teachers. The journals were note books in which the children could draw pictures, print their names, and compose stories made up of pictures and some printed words.

Compared to the meeting times in Italian schools (which we will consider shortly) things were subdued in the American preschool. Normally each child's turn at talk was 
brief with little response from the other children or the teachers. In many cases, it was difficult to hear the children and I was surprised when the teachers did not ask the kids to speak louder. On a few occasions one of the other kids said they could not hear, and then the teacher would ask for a repetition. It seemed the teachers were most interested in each individual child getting his or her turn with some short feedback.

The children often got bored waiting for their turns and had to be corrected for talking or not paying attention. The children subtly displayed their general displeasure with the boredom of meeting time with their own routine which was a negative comment on literacy. After finishing their turns when talking about a book, many of the kids held the book over their heads and let it drop behind them loudly to the floor.

Early in the school year other kids laughed when they heard the loud "thud" of the dropped book. However, when the teachers reacted negatively to both the book dropping and the laughter, the laughter was replaced by sly smiles. Yet, the book dropping continued. The symbolic and somewhat ironic character of the book dropping as a resistance to the teachers' control of this literacy event is obvious and was important in the peer culture (Corsaro, Nelson 2003).

On other occasions embellishments of literacy activities during a child's turn became a general type of resistance to the general structure of meeting time. Here creativeness in literacy activities helped the kids break free of the stifling nature of the turn-taking routine. After several weeks, one boy, David, dispensed with bringing a book to meeting time and would often offer to tell a story. These narratives were in the genre of ghost stories and they got more complex over the school term. All the stories involved David being in bed at night and hearing noises which awoke him. He told each story in a dramatic fashion, describing hearing footsteps coming up the stairs, the steps getting closer to his room, and the door opening slowly. But then he would laugh and say it was just his mother, father, his dog, and one time a visiting aunt. The other kids appreciated these stories and laughed loudly at the simple ending after the big build up. The teachers also liked the stories, but grew uneasy about having to quiet the children down every time David decided to narrate his bedroom tales.

In the Italian preschool I studied in Modena, meetings were held every day after a morning snack, and normally lasted 45 minutes to one hour. The meetings usually began with general talk about plans for the day or on Mondays or after Holidays detailed discussions about things the children had done and experienced in their days away from school. In every case, the first part of the meeting set the general tone of the overall meeting time itself; to give all the children an opportunity to have something to say or contribute as members of the group.

Sometimes discussion of plans for the day and personal experiences took up most, if not all, of the meeting time. The teachers never seemed worried about this and had a very open conception of time that was not related to strict schedules. The discussions were lively with all of the children participating and frequently interrupting each other to offer their opinions and thoughts on the comments of their teachers and peers. The Italian phrase, Secondo me (In my opinion) often preceded long turns at talk by a particular child 
with other children and the teachers quick to respond in agreement or disagreement. The importance placed on discussione of this type has been well documented in Italian schools and families (Corsaro 2018; Corsaro, Molinari 2005; Corsaro, Rizzo, 1988; Pontecorvo, Fasulo, Sterponi, 2001).

During meeting time there was also a strong display of emotion and community. The teachers were often physically affectionate with the children, but also joked and teased and were not hesitant to enter into disputes and debates with the children. I was especially taken with how natural the teachers and children were about physical affection. The teachers would often have children on their laps, give them hugs, kisses, and stroke or playfully tussle their hair.

I was also struck by what little competition there was among the children for the teachers' attention (something that was common in the American middle-class preschools I have studied). The teachers had different children on their laps at meeting time each day. I found the same thing happening to me as day to day one child and then another would hop up on my lap or grab me by the arm to pull me into play.

The teachers and children's interactive style during meeting time and more generally is, undoubtedly, related to the nature of presentation of self in Italian culture. But there is more to it than this. There had developed a strong sense of community and trust in this group that had been together on an everyday basis for nearly three years that is a key element in the Italian early education philosophy (Corsaro, Emiliani 1992; Edwards, Gandini, Forman, 1998; Malaguzzi 1998).

In the American school, most of the projects were short term in that they usually occurred over the course of one or two days. The general pattern was far the teachers to introduce the project at the end of circle time and then children would work together on the projects in small groups with teachers entering now and then to give directions and to ask and answer questions. One project involved a discussion of animals and pets and one of the teachers, Karen, brought her two large black and white dogs to visit the children. The dogs were well behaved and all but a few timid kids went up and petted and hugged them. Karen told the kids the dogs' names and pointed out that one dog was missing some fur from her tail.

She said that the dog was lost for two days and they found her caught under a fence that had barbed wire. When the dog saw Karen she pulled herself away from the fence to run to her and, in the process, lost some of her fur. The kids were very attentive to this story and showed a lot of sympathy toward the dog by hugging her and stroking her tail.

The teachers later built on the visit of the dogs and literacy events related to it by setting up a project about animals. In the following excerpt from my field notes we see two children working on the project. University Preschool, February 15, 1990.

The teachers placed copies of pictures of different types of animals for the kids to color as well as magic markers and crayons on the work tables. As Carrie and Rita color a lion they recreate the earlier story that Karen told them about the dog's tail. While coloring the girls say that their lions also got caught in a fence and lost some of their fur. The talk is complex and the girls use a lot of tag 
questions to make sure that they have each other's attention. In fact, they create a collective narrative that is modeled after, but goes beyond the teacher's earlier description. For example, they say that their lions' tails need to be polished and they pretend to do so with the magic markers. They say that the polishing makes their lions' tails as good as new. Carrie says that she will cut her lion out after she finishes coloring it. Rita says she will too and that the lions are caught in the paper and cutting them out will free them.

This example nicely captures children's extending literacy events first presented to them by the teachers in circle time. A number of literacy activities are blended into the events. First, at circle time the children visit with and pet the dogs which have been brought to school and they hear a story about how one of the dogs was injured when temporarily lost from home and caught in a fence. The teachers followed up these activities with a general project in which children could color pictures of animals. Carrie and Rita select lions to color, but tie into the earlier narrative about the injured dog. The girls collectively build their own narrative which is similar to the one they heard, but they now say the lions they are drawing were injured. They go further to remedy the situation by using aspects of their material culture (the marking pens) to heal the lions' injuries by polishing their tails with the magic markers. Their fantasy narratives are taken a step further when Rita suggests that cutting their lions out of the paper is a way of "setting them free" much in the same way that the dog was free from the fence and reunited with her owners.

In the Italian preschool the teachers and children participated together in a number of long term projects. During these projects there was frequent discussion among the whole group at meeting times and then the teachers worked with small groups or individual children on various aspects of the projects.

One project involved reading, discussing, and then reproducing (verbally, in writing, and in art) the story of the Wizard of $\mathrm{Oz}$ over around 2 months. The teachers read and discussed the book with the children during meeting time over a six week period. These discussions were often complex and animated and sometimes little reading got done. To my American mind it seemed as if we would never finish the book. The teachers were very relaxed and again did not stick to a rigid schedule, but clearly had long terms goals for the project in mind.

Near the end of the reading and discussion the children and teachers produced a large mural with the emerald castle in the background and the four main characters (constructed of items like tin foil, straw, and yarn) placed in the foreground. With the reading of the story and the mural completed, the teachers worked individually with the children, asking questions about the story, their favorite character, their favorite scene, and so on. The children's responses were recorded on audio tape. Later these responses were written up in a small workbook in which the children copied their narratives that the teachers had printed out for them - some children were able to print them out on their own. In this same workbook each child drew a picture of their favorite character and printed the name of the character under the picture. 
Later in a group meeting, the children and teachers discussed how the story was made up of a set of scenes and they decided which child would draw which scene. Over a three week period the children, working in small groups with the teacher, made sketches of their selected scenes. Each child then described his or her sketched scene to the teacher, and with spelling help, printed out this description on a separate piece of paper. The children then produced their pictures in paintings and collages.

Later, the teachers took all of the sketches and the descriptions, copied them, and made a new book of the Wizard of $\mathrm{O} z$ by arranging the scenes in order with the children's input and help. All the children received copies of the book to take with them at the end of the school year and I got one as well.

Thus, each child individually contributed again to a collective literacy project which they were able to keep as part of their material culture. In this example the collective nature of the long term project results in a blending of the school and peer cultures as the literacy event becomes part of the group experience and is important to the children's shared activity in the setting. The activity is also exciting to the children as a part of their peer culture in that the final book reflects a group production in which each child has made an individual and unique contribution.

\section{Teacher intervention in free play}

In addition to interaction with individual students and work with groups of students, teachers in both the American and Italian preschools allowed for a substantial amount of free play in the various areas of the school (inside play houses and outside swings and climbing structures) and with play materials (sand, blocks, dolls, toy animals and so on). Time for free play is essential for young children's construction of a complex and vibrant peer culture. One of the best ways to promote this peer culture is for teachers to intervene only at a last resort. Kids feel empowered and in control during free play, and quick intervention by teachers, even when there are problems and disputes, can stifle the peer culture.

On the whole teachers in American preschools (as compared to Italian teachers) were more likely to intervene in children's free play, most especially when there were disputes and conflicts. A major reason for such intervention was that the American schools were private and parents who were paying for their children's care and education expected such intervention. Parents did not like conflict and became upset if their sons or daughters complained of other children upsetting them or of not having friends. Thus the teachers were often on the lookout for conflict and worked hard to promote good peer relations.

In one example three girls (Mary, Veronica, and Megan) are playing in the outside yard of a preschool I was studying in Bloomington, Indiana. These three girls often play together and with two other girls Peggy and Shirley. In fact, Shirley and Megan often referred to each other as best friends. Today, Mary and Veronica are pretending to be pet ponies that belong to Megan. Megan, who had devised 
this play theme, has two pom-poms that she uses to direct the ponies' behavior. Shirley, who had been playing elsewhere, sees Megan and the others and comes over and asks to play. Megan at first ignores Shirley and then says she can't play. Megan, Mary, and Veronica now move to another area of the yard, and Shirley follows and again asks to play. But Megan says she cannot. After two more unsuccessful attempts, Shirley asks Mary and Veronica to be her ponies and to abandon Megan. Mary and Veronica refuse and Megan tells Shirley, "I said you can't play!"

Mary and Veronica do not actually reject Shirley, but they obey Megan and continue to take the role of her baby ponies. This gives them a bit of freedom, since they can go off to play by themselves but still be Megan's pets and return to her now and then. Shirley persists in trying to persuade Megan to let her play, but without success. Shirley now starts to cry and tells Megan, "You're hurting my feelings!" Both girls now exchange threats about not being "best buddies" anymore and not getting invited to birthday parties. Shirley also threatens Mary and Veronica, but they stick with Megan. Eventually Shirley goes and tells a teacher that Megan "is being mean and won't let me play." The teacher suggests that Shirley should play with someone else.

Now very upset, Shirley goes over and shoves Megan and Megan shoves her back. Before long both girls are crying. It is now time to go inside and when we get in the classroom, the teacher takes the two girls aside, talks about the problem. However, the girls refuse to make up. The teacher then tells them to sit on opposite sides of the room and "think about "why they are unhappy and are not being nice to each other. Later, the two girls sit at other sides of the table during snack and still do not talk to each other. However, when I return later in the day after nap time, I see Shirley and Megan sitting together and watching a video about a circus with the rest of the kids. The two girls are holding hands and actually kiss at one point.

In this example the teacher refuses to intervene at first request, but when it is clear that Shirley is upset she decided to try to get the girls to talk things over and patch up their differences. When this doesn't work she separates them (a type of "time out" that was frequently used for children who were misbehaving in the school) and tells them to "think about" why they are mad and unhappy. The strategy works and it could be argued that their dispute actually strengthened their relationship as it forced them to think more about its importance in their lives (see Corsaro 2018).

In Italian preschools I have studied teachers are much more cautious to intervene and expect children (especially children who have been together for several years to be able to settle their own disputes). In fact, the kids I studied in Bologna and Modena often considered it a failure of the peer culture when a teacher had to intervene to settle a conflict. For example in Bologna I frequently observed an interesting ritual when two children got into a dispute that escalated to the point that one child would start to cry. When the crying started the child not crying looked around to see if a teacher was nearby and then quickly offered up his or her arm for the other child to hit. And the crying child immediately stopped crying and did hit, and often hit hard. Now the other child wanted to cry, but instead sad sobbing: "Fa niente!" ("That was nothing”). Thereby ending the dispute. 
In Modena I often observed complex peace negotiations when disputes got out of hand. In such cases uninvolved kids often negotiated peace between the warring parties. Here's an example from my field notes.

Carlotta and Sofia get into a dispute over whose turn it is to ride an available bicycle. There is some pushing and shoving and Carlotta stalks off very angrily. I had noticed these two getting mad at each other before. I now see that Elisa is bringing Sofia over to Carlotta, so I follow close behind. Elisa tells Sofia and Carlotta to stay alone and work it out. Carlotta is quite upset and now begins to cry. Stefania, Federica, and Elisa now come over to Carlotta and Sofia as does Marina. Elisa tells Marina to take Sofia aside and talk to her, as she (Elisa) will talk to Carlotta. Sofia now begins to cry and is comforted by Marina and then by Elisa and Stefania. Marina now takes Sofia to the teacher briefly, and then the two go to get Elisa who is with Carlotta.

Meanwhile, Renato comes over and talks with Carlotta and Elisa. Marina brings Sofia over. Marina makes a joke and everybody laughs. But Carlotta and Sofia are still upset, and Sofia says that Carlotta is a "big liar." The others try hard to overcome this problem. Eventually, the two seem to agree not to fight any more, but they have not made up. Later when the children go inside, wash up, and sit down waiting to go to lunch, I notice that Carlotta and Sofia have made up and are sitting next to each other. They are very happy and laughing. They are also glad when Marina (who is one of the waiters for lunch) selects the two of them for her table. They run off with their table mates with hands on shoulders.

This was one of several examples where a small group of children (usually 4 or 5) worked together to settle a serious rift between two of their playmates. In this instance and in almost all of these cases, a teacher or teachers became aware of the problem, but left the children alone to settle things themselves. The children saw serious conflict between or among their peers as a threat to the strong group identity of the peer culture and worked collaboratively to reduce this threat.

We can contrast this example with the early one we discussed in the Bloomington preschool. Here when the two girls, Megan and Shirley, got into a serious dispute other children (even the two girls playing with Megan when Shirley tried to enter the play) stayed out of the conflict. In short, the dispute was seen as a private matter and somewhat external to the group. The teacher worked with the two American middle class girls to get them to talk things over and eventually they made up. However, in the Modena preschool disputes, as we have seen, are not viewed as private matters but threats to the group and peer culture as a whole. I would argue that this difference is related somewhat to cultural aspects (Italian and Americans look at disputes in different ways), but also to a number of interrelated factors including the structure and organization of the schools (how long the children remain in the group and with the same teachers, whether the schools are private versus public) and the nature of teacher-child relations. 


\section{Families and peer culture}

In all the preschools I have studied the kids created vibrant peer cultures which reflected the joy, wonder, and complexity of their childhoods. In the American preschools the complexity of the kid's culture was by and large hidden from most adults beyond the teachers and a few parents. In the private not-for profit preschools I studied in Berkeley, California and Bloomington, Indiana, the overall quality and resources of the schools were high and there was some parent involvement.

Not-for-profit private preschools often provide high quality teaching staffs and curricula as well as resources because tuition revenue is used only to pay the program's staff. For-profit private preschools, on the other hand, are normally of lower quality because teacher pay and investment in resources are often kept to a minimum to increase profits. Parental involvement in the private (not-for-profit) preschools I studied normally occurred outside the classrooms and was primarily administrative, especially by parents who served on the preschools' boards of directors. There were, however, a few special events throughout a given school year like family dinners and musical and other talent performances by the children for their families. There were also a few field trips into the local communities like visits to zoos or museums. These events helped to bring parents and kids together and also involved the kids in the wider community to some degree.

The Head Start programs (government supported early education for very poor children) I have studied lacked the resources that were typical in the American private preschools or the Italian government preschools I have studied. Although, federal government support of Head Start has increased since the time of my study, the programs are still limited in terms of the number of children covered and range of program activities. The programs were in general of good quality but were limited to half day, some portion of which was spent on structured language and cognitive tasks based on a compensatory orientation.

That is, this part of the curriculum assumed that poor children lacked cognitive and language skills and needed such drills to catch up or have a "head start" for kindergarten. I found, on the other hand, that the drills (while teaching children to raise their hands and take turns in lessons in ways comparable to public kindergarten and first grade) often confused the kids and led them to believe that there was only one right answer for any question.

Despite the half day limitation and problems with the compensatory nature of some aspects of the curriculum, the Head Start programs were highly valuable regarding the kids' social and emotional development. The kids developed a strong peer culture which was supported by a group of caring adults in the Head Start centers. In fact, the Head Start centers are best described as small communities that emphasized collective values and provided something approaching an "extended family."

In a typical day at the centers, the average child came into contact with a wide range of adults: teachers and teaching assistants, visiting parents, bus drivers, administrative staff, social workers, speech therapists, custodians and cooks. Although the kids spent the overwhelming majority of their time at the centers with the teachers and assistants in 
their particular classrooms, they knew all the adults' last names and frequently exchanged greetings and playful talk. These adults also knew the children well. In fact some adults had particular favorites among the kids they would talk and joke with in the hallways and when they entered the classrooms.

This strong support from caring adults was very important for the Head Start children, many of whom came from single parent families and lived in poor and dangerous neighborhoods with limited opportunities for positive interactions with adults or other kids. Furthermore, the Head Start programs encouraged parental involvement (several parents worked in the centers regularly) and the teachers visited and supported parents in their homes.

The Italian preschools I studied in Bologna and Modena promoted kids' construction of complex peer cultures, which both enriched their childhoods and contributed to their development of social, language, and cognitive skills. The programs have a long history in northern Italy dating back to the 1960s and high quality early education is the norm throughout Italy today with over $96 \%$ of all three to five year old children attending.

Most of the legislation related to child care instituted in the late 1960s and early 1970s in Italy was the result of intense periods of social and political struggle which followed the Italian economic boom of the 1950s and 1960s. Much of the collective and highly public political mobilization of this period was directly tied to the mass migration of Italians from rural areas throughout the country to major cities, primarily in the North. This type of collective action had a long history in certain regions of the North, most especially Emilia Romagna, the province where Bologna and Modena and the schools I studied are located as well as the famous Reggio-Emilia schools. As a result, child-care and early education issues were caught up in labor militancy, youth movements, the women's movement, and other urban protests.

The general orientation of early childhood education in Italy reflects the collective and communal movements from which it was born. The preschool is seen as a place of life for children. Activities such as playing, eating, debating, and working together are considered just as important as those that focus on individual cognitive or intellectual development. This communal activity is evident in the organizational structure of preschools as well as the wide range of social, verbal, and artistic projects making up the curriculum that stress the relationship of the preschool with the family, community, and children's peer culture (Corsaro, Molinari 2005; Edwards, Gandini, Forman 1998).

Regarding the structure of the preschools, in Bologna a mixed-group of 35 children with five teachers attended all day programs from September until July with a new group of children entering and another group leaving over the three years I observed. In Modena I studied a group of five-year-olds who had been together for three years with the same two teachers. This structure of keeping children together with the same teachers over the three years of preschool builds strong communal bonds among the children and between the children and parents. It is also important in parental participation in the school programs as parents get to know each other well and develop strong relationships with 
the teachers. In this way the preschool is something more than an educational institution in Italy, it is often a social and community organization for families with young children.

One project in Bologna involved planning for, making, and reconstructing visits to the homes of the older kids during the spring of their final year at the school. In my first year in the preschool I was introduced to this project in an indirect way when a boy, Felice, told me: "Bill, you're coming to my house." I was not sure how to respond to this and just nodded and said, "That's good." I assumed that perhaps Felice's parents were going to invite me for a visit.

However, a few days later in a group meeting the teachers told us about the family visits. Then each of the older kids talked about their families and the preparations they were making for our visits. All of this sounded really exciting to me and the three-year-old kids who had not been on one of these visits before.

I especially remember the walk to Felice's house. His home was very near the school and located in a residential and shopping area near my apartment. Thus I knew many of the merchants with whom we stopped and chatted with along the way. The storekeepers knew about these annual outings and looked forward to the opportunity to talk with and admire the kids. We also talked with many shoppers (both men and women) as we reached the first busy street on our way to Felice's house. In fact, these conversations seemed to delay our progress from my American perspective and I wondered if we would ever get to Felice's house! However, the teachers and kids were unconcerned and enjoyed the conversation and attention of the adults in the local community.

We eventually continued our journey and left the busy thoroughfare, walking down a small side street that came to an end in front of the large apartment building where Felice's family lived. As we approached the front door of Felice's building, several children ran up and were taking turns pressing the bell. Antonia, my partner on the walk, tugged on my arm to hurry up to the door. When Antonia finished ringing the bell, swept up in the moment I also gave it a long ring. Everyone laughed and one of the teachers said, "That Bill, always one of the kids. Enough. Let's go in."

Felice and his younger brother, Marco, peered down over the railing at us as we climbed the four flights of stairs to their apartment. The smile on Felice's face was unforgettable. When we arrived we were greeted by Felice's parents and three of his grandparents (one of his grandfathers was no longer alive) who were all present for the big day. Felice's parents escorted the teachers into the kitchen while I was pulled off to Felice's room with the other kids. We inspected all of Felice's toys which included an impressive collection of "I Puff" (small replicas of cartoon characters - Smurfs, in the United States - that were popular among the kids at that time). Eventually, we all went off to the kitchen where Felice's mother served a wide variety of scrumptious snacks. Before we left Felice's father presented me with homemade wine and salami. That evening after I summarized the event in my notes, I reflected on my strong emotional reactions to the event and I wrote: "It was a good day!"

For several days after a home visit, the teachers and kids first verbally and then artistically reconstructed the experience. The artwork contained a series of pictures that 
visually captured the major phase of the event with each child contributing in some way to each picture. The detail of the pictures was striking. In a depiction of our walk to Felice's home, for example, some children drew the cars on the street, others drew individual members of the group (teachers, kids, and me), while still others drew shops while their classmates designed clothes to put in the shop windows. These pictures were then prominently displayed in the school (along with artwork related to other projects) until the end of the year when they were taken home by the older children to keep as mementos.

In this project the kids think about, discuss, and artistically reconstruct their relations with the school, family, community and each other. They collectively reaffirm the emotional security of these bonds while reflecting on how the nature of these attachments changes as they grow older. In the process the kids gain insight into their changing position in the school, peer, and wider adult culture.

In addition to long term projects family involvement was high in the preschools in both Bologna and Modena. Parents and grandparents were always welcome in the school and many stayed each morning for a half hour or so talking with the teachers, inspecting artwork children had created in various projects, and interacting with the children. Parents and grandparents often visited outside the school with each other after bringing their children in the morning and picking them up in the afternoon. In this way preschool served as centers for social discourse and civil society. In both preschools there were "end of the year" parties where children gave singing and dancing performances to large groups of parents and grandparents. In Modena there was both a party for the whole preschool and a special party just for each group organized by the parents and teachers. At the party for my group the kids performed dancing and singing routines they had practiced for many weeks. The parents and some grandparents also engaged in certain of the dances and participated in games with the kids as well as prepared a large meal. The parents presented the teachers with expensive gifts and even provided a gift (a beautiful beach towel) for me as a member of the group.

\section{The community and peer culture}

In the private preschools I have studied in the United States the children had little direct involvement with the surrounding community. The children took one or two field trips each year to a museum, botanical garden, or state park. One reason for such few trips was a lack of means of transportation as the centers did not have a bus and renting busses was not easily arranged and costly. Also many parents were somewhat concerned with the safety of their children on such field trips, and they felt they could provide such activities and experiences for their children in the family.

Things were quite different in the Head Start centers I studied in the United States. Because the children were bussed to the Head Start center, the buses and drivers were available to take the kids and their teachers on numerous field trips over the course of 
the year. Many parents also participated in these events. The kids visited parks, museums, zoos, department stores for Christmas and Easter displays and activities, and work places like post offices and fire stations. The kids were always treated warmly by the adults they met in these various community contexts. And quite simply the kids loved these field trips. While such activities might be taken for granted by many middle and upper class kids, they were special to the Head Start children. The kids talked about and anticipated the trips days in advance and often incorporated features of the activities in their peer play for many days following the events. In this way these activities made the kids more visible in their community and also developed support and appreciation for and contributed to the kids' childhoods and peer cultures.

My experience with the kids in Modena was especially meaningful for me because I went on with the group to first grade and continued to keep in touch with the four first grade classes throughout the five years of elementary school. As a result, I was able to observe and experience many of the events and activities in Modena in which a strong civic society was constructed around these children and their families. By civic society I mean a collective celebration of civic engagement, people's connections with and participation in the life of their communities. In the United States examples of such civic society might be neighborhood block parties, bowling leagues, union picnics and ethnic street festivals. Although such events still exist, many argue that they a fading from the lives of many Americans and their children (see Corsaro, Johannesen 2014; Putnam 1996, 2015).

Civic engagement was strong in Modena and often involved and even centered on children. In fact, preschools and elementary schools were often the site and kids the focus of many civic activities. I was first introduced to this type of civic engagement in the celebration of Carnevale (our Mardi Gras) during my first month in the Modena preschool. First, in the school there were two days of celebration with the three- to -five -year-old kids and their teachers in costume, dancing, singing, eating candy and pastries and generally having a grand time. Then there was also a general celebration for all Modena's children, including my eight year old daughter and all the kids I studied, in the main square of the city. Here kids, in a wide variety of colorful costumes, gathered with parents and grandparents to run, play, throw streamers, listen to music, and buy candy and other treats from street vendors.

This was one of several events that occurred both in the school and at the more general city or community level. Another was a concert of traditional children's songs performed by five-year-olds from all the preschools for all the people of the city. The performance was preceded by months of preparation and practice by the children under the direction of the music teachers in each preschool. The children had one rehearsal with all the kids and music teachers before the big performance which was a spectacular and highly successful civic event with many proud parents and grandparents in the large audience.

Just as important, all the preparation, practice, and pride in the performance made the singing of the songs a key element in the kids' peer culture during the last months in the preschool. They often sang or hummed the songs during work on projects and in 
free play. I especially remember their singing of the songs at another civic event in the preschool, the festa dei nonni ("party for grandparents").

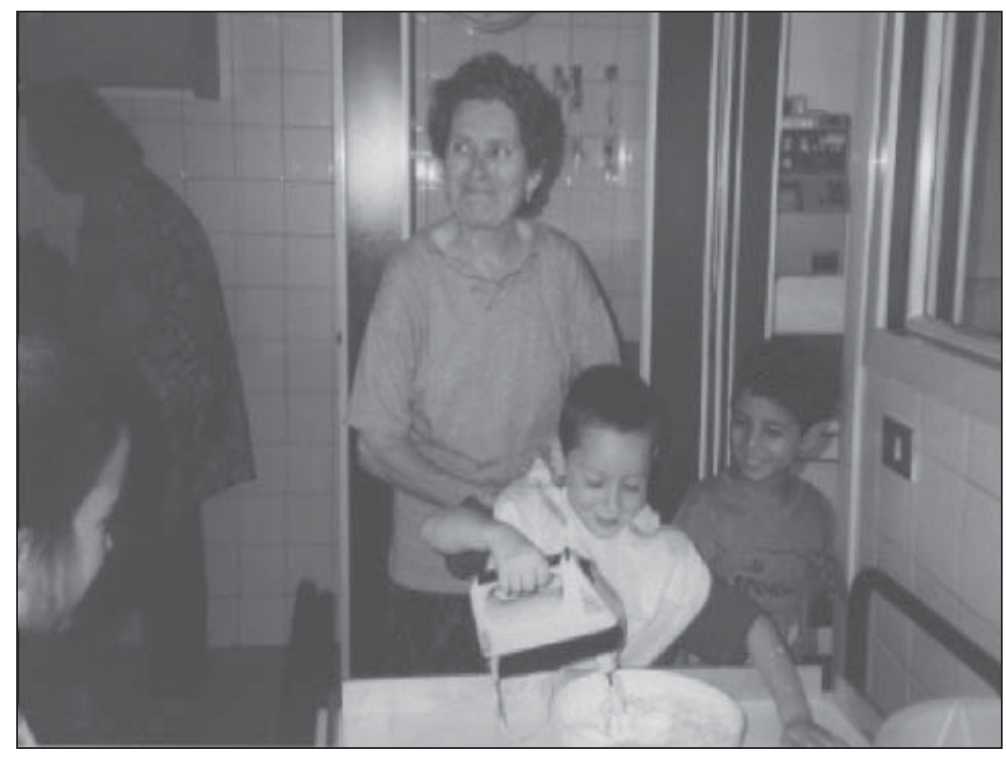

Figure 1. Making desserts at the festa dei nonni

Source: Author's archive.

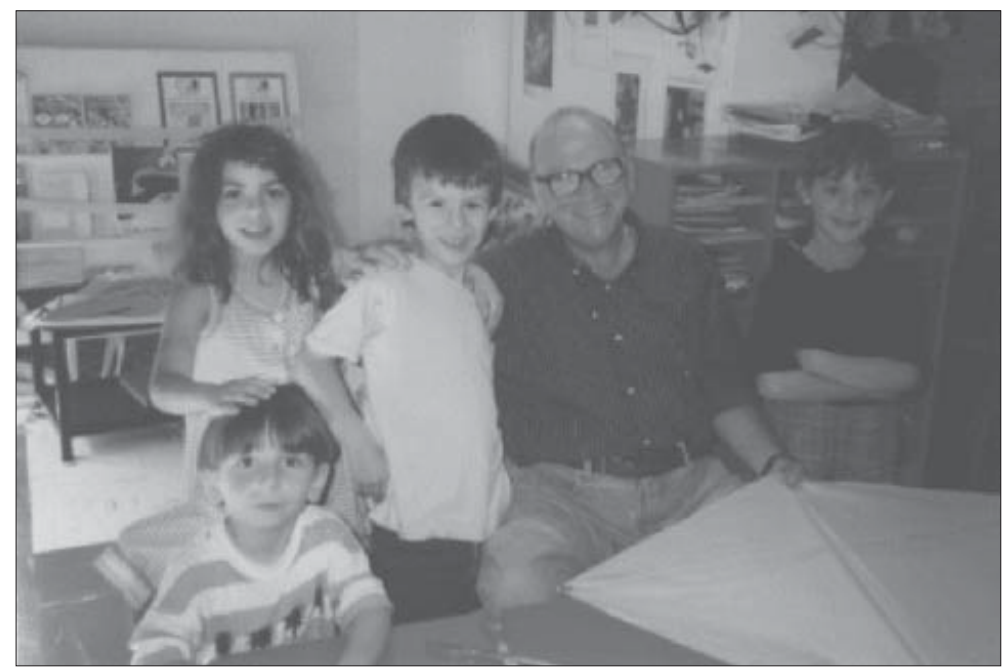

Figure 2. Making kites at the festa dei nonni

Source: Author's archive. 
At the festa dei nonni almost all the grandparents of the kids who lived in Modena attended. There were many activities in which the kids and grandparents worked together. Some grandmothers with girls and boys sewed new outfits for dolls, while other grandmothers went up to the kitchen with a group of kids to make desserts to have after the big meal that the school's cooks were preparing. Some grandfathers worked outside in the garden with one group of kids, while another made kites as we see in Figures 1 and 2.

We later took the kites out into the yard, and the kids took turns flying them around. My job was fetching the wayward kites out of the trees without damaging them.

What I remember most, however, happened right before lunch. The kids sang several of the songs they had earlier practiced so often and performed for the city wide concert. I had heard these songs over and over. I now knew them by heart. As the kids sang the first two songs, I sang along with them, softly mouthing the words. In the middle of the third song, the kids, who were sitting in small chairs, laid their arms over each others' shoulders and began to sway with the music. Their faces were beaming. I looked at the grandparents. They were all misty-eyed. So was I (see Corsaro 2018; Corsaro, Molinari 2005).

As I noted earlier I stayed with the children in Modena as they made the transition to elementary school and eventually on to middle school as well. As the community wide songfest for all of the children in their last year of preschool was a sort of marker of a right of passage, a similar event occurred for all fifth graders five years later. This was a special sports day held on a beautiful, spring Saturday in a large park in Modena. Children arrived in the park and wore tee shirts of different colors representing their schools. All of the groups from each school were gathered together in one large group for some discussion about the different sports activities which were set up around the park. The organizers of the events (young and older men and women) then led the kids in some singing and orchestrated movements to some well known Italian folk and pop music.

Afterwards the kids were set free to explore the different sports activities often with their parents following along as spectators. The kids had many (about 20 sports to choose from, everything from judo to windsurfing). It was a great day and it certainly contributed to the kids peer culture as well as the civic society of Modena.

\section{The ethnographer and peer culture}

I want end this discussion with some brief reflections on my own relations with children as an adult researcher. Over the years I have kept in touch with many of the kids I have studied after we have spent a year together. In a few cases (especially of one boy in the Head Start Center, one girl from the Bologna preschool, and three children from the Modena preschool) some of the children have become close friends of mine and my family as I have watched them grow up visiting them multiple times in the U.S. and Italy. Two of the children from Modena have visited me in the United States. 
In Modena, I had the opportunity to follow a large group of children throughout their elementary school education (Corsaro, Molinari 2005). For about 20 of these 75 children I also knew them in preschool. After an extended period of ethnographic research from February until July, 1996 in the preschool, I then went on to first grade with these preschool children and met and interacted with their new classmates and teachers in first grade until late December, 1996. I then returned each spring in May and June and observed until they finished elementary school in June, 2001. I also returned to Modena and interviewed several of the children from the preschool and their families about how they were doing in middle school and high school. I also gave a talk about our work which many of the teachers and some of the parents and children attended.

During periods when I was away from the children I sent cards, letters, and small gifts to the kids and their teachers. In response the kids sent letters back to me. These letters capture in many ways the close bonds I have established with the children. More importantly, they demonstrate how they continued to share their lives with me and also captured their developing use of literacy.

Fabrizio, wrote me a letter regarding his experiences during carnevale. In his letter Fabrizio has drawn an elaborate picture of himself dressed up as a ghost. The text in the drawing represents Fabrizio talking, telling me that he is dressed up as a ghost. The text does not include any punctuation, and the word "io" [I] should be capitalized, but, for all intent and purposes, it is correct. This drawing shows Fabrizio's ability to combine artwork with grammar, thus showing his own literacy ability. Further, the content of the drawing suggests that Fabrizio uses his own peer culture in his writing and his drawing, as he chooses to draw a picture of himself dressed in his ghost costume for carnevale. Dressing as a ghost is what is important to him and what he wishes to communicate. Another instance of children's culture in Fabrizio's drawing is his incorporation of text into the picture. In order to display his voice talking, he draws a bubble coming from his mouth which includes the words that he is saying. This bubble is very reminiscent of the ways that characters talk in comic books, and is therefore reflective of a children's material culture.

In the letter, Fabrizio tells me things about his life that are important to him. He begins the letter by telling me that he likes me and wonders if I am sick (I had not written to the children recently). This opening statement shows Fabrizio's current state, and also a relevant concern to my current state. He then supplements his affection and concern for me by sending me "many big kisses." In the next section of the letter, Fabrizio writes of how he dressed up as a ghost. This comment directly reflects the content of his drawing, and also provides us with evidence that Fabrizio is writing about what is important to him. We see further that he writes about his life, telling me about a film (the "blue arrow") that he saw with his classmates. Also, he notes the group activity of making posters to collectively recreate the film they saw. The making of the posters, further, could be considered a literacy project - in the vein of artwork with words and phrases - and it is, therefore, interesting to see that Fabrizio writes about this in his letter, suggesting that literacy activities are important and fun (see Corsaro, Nelson 2003). 
The content of Fabrizio's letter shows us that children will write about themselves and what is interesting to them including aspects of their peer culture. This, again, allows us to conclude that children creatively and actively participate in their production of literacy-related artifacts. We are given final evidence of such creativity at the end of Fabrizio's letter, after he signs his name. He draws an elaborate picture of an airplane which carries a special message to me, in the form of a sign tied to the back of the plane. This part of the letter is very compelling, as it shows how children often incorporate text and artwork, and do so in highly creative ways. Instead of merely writing a post-script to me, telling me that he sends him many big kisses, Fabrizio's airplane (high in the sky for all to see) is sending out his message to me. This example aptly captures how children's creativity and peer culture are pervasive in their literacy activities.

Overall, longitudinal ethnography has allowed me not only to enter the children's worlds and become a friend, but to maintain these friendships and for them to mature to a new level as the children grow older. In this way the children are not only my research participants, but close friends and they and their families have become an important part of my life in personal ways that transcends the research experience (Corsaro, Molinari 2017).

\section{References}

Corsaro W.A. (2018). The Sociology of Childhood. $5^{\text {th }}$ ed. Sage, Thousand Oaks, CA (in printing). Corsaro W. (2004). Peer culture and adult-child relations. "Stockholm Lectures in Educology", 3. Stockholm University, Department of Education.

Corsaro W.A., Emiliani F. (1992). Child care, early education, and children's peer culture in Italy, in: M.E. Lamb, K.J. Sternberg, C.-Ph. Hwang, A.G. Broberg (eds.), Child Care in Context. Lawrence Erlbaum Associates, Hillsdale, NJ: 81-115.

Corsaro W.A., Johannesen B. (2014). Collective Identity, Intergenerational Relations, and Civic Society: Transition Rituals among Norwegian Russ. "Journal of Contemporary Ethnography", 43: 331-360.

Corsaro W.A., Molinari L. (2005). I Compagni: Children's Transition from Preschool to Elementary School. Teachers College Press, New York.

Corsaro W.A., Molinari, L. (2017). Entering and observing in children's worlds: A reflection on a longitudinal ethnography of early education in Italy, in: P. Christensen, A. James (eds.), Research with children: Perspectives and Practices. $3^{\text {rd }}$ ed. Routledge, New York: 11-30.

Corsaro W.A., Nelson E. (2003). Children's collective activities and peer culture in early literacy in American and Italian preschools. "Sociology of Education", 76: 209-227.

Corsaro W.A., Rizzo T.A. (1988). Discussion and friendship: Socialization processes in the peer culture of Italian nursery school children. "American Sociological Review", 53: 879-894.

Edwards C., Gandini L., Forman G. (eds.) (1998). The Hundred Languages of Children: The Reggio-Emilia Approach - Advanced Reflections. Ablex, Greenwich, CT. 
Malaguzzi L. (1998). History, ideas, and basic philosophy: An interview with Lella Gandini, in: C. Edwards, L. Gandini, G. Forman (eds.), The Hundred Languages of Children: The Reggio Emilia Approach - Advanced Reflections, $2^{\text {nd }}$ ed. Ablex, Norwood, NJ: 49-97.

Pontecorvo C., Fasulo A., Sterponi L. (2001). Mutual apprentices: The making of parenthood and childhood in family dinner conversations. "Human Development", 44: 340-361.

Putnam R. (1996). The strange disappearance of civic America. "American Prospect", 24: 34-50.

Putman R. (2015). Our Kids: The American Dream in Crisis. Simon \& Schuster, New York. 